\title{
Double-blind Trial of Four Hypotensive Drugs (Methyldopa and Three Sympatholytic Agents)*
}

\author{
V. VEJLSGAARD, M.D.; M. CHRISTENSEN, M.D. ; E. CLAUSEN, M.D.
}

Brit. med. F., 1967, 2, 598-600

In general, drug treatment of hypertension is started with a diuretic. If such therapy is not successful another hypotensive drug is added, either a specific sympatholytic agent or methyldopa.

In order to be as objective as possible regarding which of these methods of treatment is the best a double-blind trial was carried out ; this included two of the known hypotensive drugs, guanethidine (Ismelin) and methyldopa (Aldomet), and two new drugs, guanoxan (Envacar) and guanoclor (Vatensol).

\section{Chemistry and Pharmacology}

Guanethidine is a sympatholytic agent (Maxwell et al., 1959), and its effect is predominantly a lowering of the blood pressure in the erect position, whereas only a slight reduction is obtained In the supine position (Page and Dustan, 1959). Guanethidine reduces the concentration of catecholamine both centrally and peripherally, but not in the superior parts of the central nervous system. Intestinal absorption is constant, its elimination is mainly renal and slow, and therefore the dose should be determined cautiously in cases of impairment of renal function. When the drug is administered intravenously the cardiac output and renal blood flow are distinctly reduced, and bradycardia is a characteristic finding.

Methyldopa (alpha-methyl-3-4-dihydroxyphenyl-alanine) is a decarboxylase inhibitor. Absorption takes place rapidly, but varies from patient to patient-a fact without positive correlation to the antihypertensive effect. The mechanism of the drug has not yet been explained in detail. Its decarboxylase inhibitory action is not alone responsible for the antihypertensive result ; other decarboxylase inhibitors have no effect at all on the raised blood pressure. Metabolites of methyldopa such as methylnoradrenaline could be the effective agents; a replacement of noradrenaline with this metabolite in tissue stores might act as a false transmitter on stimulation. Methylnoradrenaline has in itself some, though poor, pressor effect. This hypothesis could explain the poor orthostatic effect of methyldopa and the missing clinical sympatholytic action (Sannerstedt et al., 1962 ; Onesti et al., 1964 ; Prescott et al., 1966).

Guanoxan is 2-guanidinomethylbenzo-1, 4-dioxan. Consequently it is a guanethidine-ring with benzodioxane in the side chain. Guanoxan causes a reduction in the concentration of catecholamines in both the hypothalamus and the adrenal medulla, and peripherally. It has been shown that cats treated with guanoxan present reduced avoiding reactions and inhibited vasoconstrictive response in the skin on hypothalamic stimulation. In dogs treated with guanoxan a reduced effect of injected adrenaline due to adrenergic blockade has been found (Brit med. F., 1964a ; Davey and Reinert, 1965); similar findings were made with benzodioxane alone. In animal experiments guanoxan differs from guanethidine in that it blocks the alpha-receptors and reduces the concentration of catecholamine in the hypothalamus. On oral administration of guanoxan the influence on the blood pressure becomes measurable after 24 hours and maximal after 48 hours.

- From the Department of Medicine, Diakonissestiflelsen, and the Department of Medicine, Bispebjerg Hospital, Copenhagen, Denmark.
Guanoclor is 2-(2,6-dichlorphenoxy) ethylamino-guanidine. In animal experiments and in experiments in vitro reduction of the concentration of catecholamine was found both in the hypothalamus and the adrenal medulla, and peripherally. Furthermore, on administration of guanoclor a peripheral sympathetic blockade has been demonstrated.

In-vitro experiments have shown that guanoclor inhibits the enzyme dopamine-beta-oxidase: Correspondingly, it was possible to show a considerable reduction in the excretion of adrenaline both in experimental animals and in patients during hypotensive treatment with guanoclor (Brit. med. F., 1964 ; Lawrie et al., 1964b). A similar reduced excretion was not observed in patients who were treated with guanoxan or guanethidine. With oral administration of guanoclor the influence on the blood pressure becomes measurable after 24 hours and maximal effect is obtained after 48 hours.

Since guanethidine and methyldopa were introduced for the treatment of hypertension in the late 'fifties many reports have been published on their clinical application and side-effects (Cass et al., 1960 ; Dollery et al., 1960 ; Oates et al., 1960 ; Sannerstedt et al., 1961 ; Bayliss and Harvey-Smith, 1962; Daley and Evans, 1962 ; Gillespie et al., 1962 ; Lauwers et al., 1963 ; Lowther and Turner, 1963).

Only a few clinical trials of guanoxan and guanoclor have been published. With respect to the former drug, two independent studies showed a good degree of control in $58 \%$ of 62 patients (Peart and MacMahon, 1964) and 48 patients (Montuschi and Lovel, 1964). The side-effects reported were lack of energy, nausea, diarrhoea, and impotence, as well as failure of ejaculation. On guanoclor the blood pressure was well controlled in $60 \%$ of 39 patients (Lawrie et al., 1964). Three patients stopped taking the drug because of dizziness and muscular fatigue.

\section{Material}

Forty-two patients were selected from among our hypertensive outpatients. All had been admitted previously for assessment. All had normal urinary excretion of catecholamine.

Two patients were excluded from the study; one had moved from the area, and the other did not want to continue after having been given the first agent. The material therefore comprised 20 men, average age 50.4 (34-65) years, and 20 women, average age $48.1(29-66)$ years.

In all cases the diagnosis was essential hypertension, with the exception of a 55-year-old man with chronic glomerulonephritis. No patients with severe reduction in renal function were included. The average serum creatinine value was 1.5 $\mathrm{mg} . / 100 \mathrm{ml}$, and in only two patients was it above $2 \mathrm{mg} . / 100$ $\mathrm{ml}$.

On the basis of the ophthalmological findings all the patients were assessed as having a moderate to severe increase in blood pressure. The findings, according to the Keith-Wagener scale, were: three in grade $0-I, 13$ in grade II, 16 in grade III, and eight in grade IV. Blood pressure values recorded without treatment immediately before the present study were not avail- 
able, since many of the patients had been under treatment for several years, and it was thought unjustifiable to stop the antihypertensive therapy completely.

In all the patients the hypertension was so severe that diuretic therapy alone could not produce an acceptable level of blood pressure. At the time the study was started the diuretic regimen in all patients consisted of $4 \mathrm{mg}$. of polythiazide (Renese). Our own investigations show that this dose had a maximum effect on the blood pressure. Potassium was not given permanently, but if the serum potassium was below 3 $\mathrm{mEq} / 1.2 \mathrm{~g}$. of potassium chloride daily was added. Serum potassium levels were estimated at least once a month. In addition to the diuretic therapy three patients had received hydrallazine (Apresoline) (100-400 mg. daily) over a long period. This medication was maintained constantly throughout the study.

\section{Method}

The patients were examined on an outpatient basis at intervals of one to three weeks. An assistant recorded the blood pressure after the patient had rested for at least 10 minutes and immediately afterwards in the standing position. The examinerthe same person during the whole investigation-then fixed the had to be withdrawn because of side-effects-pronounced orthostatic dizziness, dizziness on exertion, and pronounced discomfort and fatigue. Subjective complaints were often made before the postural change in blood pressure could be recorded at the follow-up examination. One patient did not want to continue in the trial. The drug concerned was excluded from the blind trial. At the termination of the study it was found to be guanoclor.

The results with the other three drugs-guanethidine, methyldopa, and guanoxan - are given in Table I. It will be seen that a satisfactory result without side-effects or with slight side-effects was obtained in 34 patients with methyldopa, 25 with guanoxan, and 20 with guanethidine. The average doses required to reach this result were $1,000 \mathrm{mg}$. of methyldopa, $30 \mathrm{mg}$. of guanoxan, and $33 \mathrm{mg}$. of guanethidine. It should be noted that the mean blood pressure in both the lying and the standing positions was fairly uniform in the three groups.

In a few patients the blood pressure was satisfactory, according to definition, but there were severe side-effects. When sympatholytic agents were used the side-effects were mainly postural troubles ; this is apparent from the mean blood pressure recorded in the lying and standing positions shown in Table I.

Some patients appeared to be extremely resistant to the drugs used, even when, as shown in Table I, the dose was increased

TABLE I

\begin{tabular}{|c|c|c|c|c|c|c|c|c|c|c|c|c|c|}
\hline & \multirow{3}{*}{. } & \multicolumn{4}{|c|}{ Guanoxan } & \multicolumn{4}{|c|}{ Methyldopa } & \multicolumn{4}{|c|}{ Guanethidine } \\
\hline & & \multirow{2}{*}{$\begin{array}{c}\text { No. } \\
\text { of } \\
\text { Cases }\end{array}$} & \multicolumn{2}{|c|}{ Mean B.P. } & \multirow{2}{*}{$\begin{array}{l}\text { Dose } \\
\text { (mg.) }\end{array}$} & \multirow{2}{*}{$\begin{array}{c}\text { No. } \\
\text { of } \\
\text { Cases }\end{array}$} & \multicolumn{2}{|c|}{ Mean B.P. } & \multirow{2}{*}{$\begin{array}{l}\text { Dose } \\
\text { (mg.) }\end{array}$} & \multirow{2}{*}{$\begin{array}{c}\text { No. } \\
\text { of } \\
\text { Cases }\end{array}$} & \multicolumn{2}{|c|}{ Mean B.P. } & \multirow{2}{*}{$\begin{array}{l}\text { Dose } \\
\text { (mg.) }\end{array}$} \\
\hline & & & Lying & Standing & & & Lying & Standing & & & Lying & Standing & \\
\hline $\begin{array}{l}\text { Satisfactory control. Side-effects: none or mild } \\
\text { Satisfactory control. Severe side-effects } \\
\text { No or poor control in spite of increase in dose } \\
\text { Poor control because of pronounced side-effects }\end{array}$ & $\begin{array}{l}\cdots \\
\cdots \\
\cdots\end{array}$ & $\begin{array}{r}25 \\
5 \\
3 \\
7\end{array}$ & $\begin{array}{l}115 \\
110 \\
136 \\
136\end{array}$ & $\begin{array}{r}104 \\
92 \\
122 \\
116\end{array}$ & $\begin{array}{r}30 \\
30 \\
104 \\
66\end{array}$ & $\begin{array}{r}34 \\
2 \\
4 \\
0\end{array}$ & $\begin{array}{l}114 \\
121 \\
135\end{array}$ & $\begin{array}{l}108 \\
120 \\
130\end{array}$ & $\begin{array}{l}1,000 \\
1,750 \\
2,500\end{array}$ & $\begin{array}{r}20 \\
5 \\
1 \\
14\end{array}$ & $\begin{array}{l}115 \\
118 \\
163 \\
135\end{array}$ & $\begin{array}{r}107 \\
98 \\
147 \\
113\end{array}$ & $\begin{array}{r}33 \\
44 \\
125 \\
49\end{array}$ \\
\hline
\end{tabular}

dosage of tablets for all patients according to the recorded blood pressure and possible side-effects.

The response was assessed according to the mean blood pressure while lying, and calculated as the diastolic pressure plus one-third of the amplitude.

The criteria for satisfactory response were: for those below 40 years, $115 \mathrm{~mm}$. $\mathrm{Hg}$; for those aged 40 to $50,120 \mathrm{~mm}$. Hg ; and for those over $50,130 \mathrm{~mm}$. $\mathrm{Hg}$.

The study was conducted as a double-blind trial. All tablets were made to look identical and were delivered from Pfizers in boxes labelled A, B, C, and D. The code remained unknown until the trial was finished. The tablets contained guanethidine $12.5 \mathrm{mg}$., methyldopa $250 \mathrm{mg}$., guanoxan $12.5 \mathrm{mg}$., and guanoclor $20 \mathrm{mg}$. The initial dosage of all drugs was half a tablet twice a day, increased according to the effect. If more than four tablets were needed the dosage was divided into four daily doses.

The dosage was increased until satisfactory response was obtained-that is, no reduction in the blood pressure in spite of higher doses-or the occurrence of prohibitive side-effects. In cases where the response was satisfactory the requisite dose was maintained for 2-3 controls-that is, one to two months.

At the beginning of the trial and when any change of drug was made, the transition took place gradually, the drug in use being tailed off durng the increase in dosage of the next.

The sequence of the drugs was fixed systematically, so that no sequenoe became more frequent than others. Each drug was given for periods of two to six months, on an average for three and $a$ half months.

\section{Results}

One of the four drugs had a satisfactory effect in only 3 of the 11 patients who started with it. In the remaining eight it considerably. In seven patients treated with guanoxan and in 14 treated with guanethidine the side-effects were so troublesome that the dose could not be raised, though further reduction of the blood pressure was required.

\section{Side-effects}

The side-effects are shown in Table II. In several cases those classified as slight were of a temporary nature. They often disappeared if the same dose was maintained for some weeks, after which time the dose could be increased without reappearance of the side-effects. Postural dizziness was observed in connexion with all three agents, though the incidence of severe, not temporary, dizziness was higher during treatment with guanoxan, and particularly with guanethidine. Almost coincidentally a pronounced dizziness was experienced during exercise.

The patients often complained of fatigue during treatment, but this symptom was usually transient. Only in one patient on methyldopa and in three patients on guanoxan was this side-effect more pronounced.

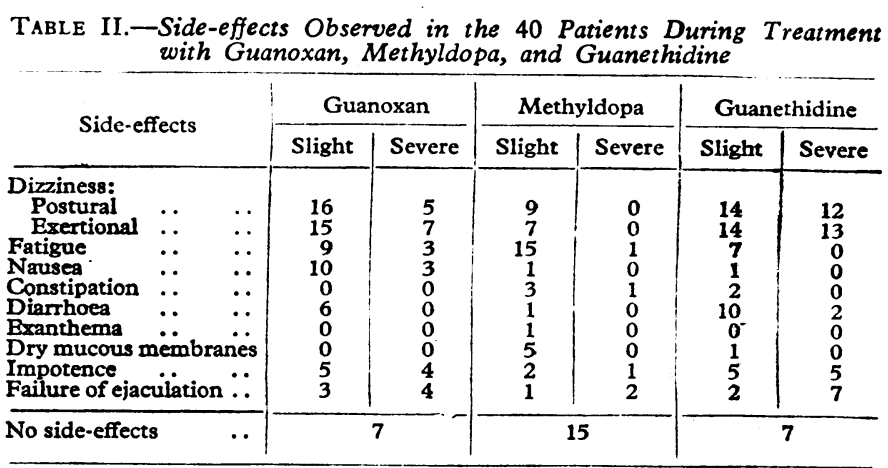


Thirteen patients complained of nausea after ingestion of guanoxan tablets, especially in the morning. As a rule the nausea could be reduced by taking the tablets with meals. One patient developed a dry squamous eruption on the back of his hands during treatment with methyldopa. He had had similar eruptions previously when taking the same drug. Many patients complained of impotence and failure of ejaculation. These symptoms were observed with all the drugs, but were most troublesome with guanoxan and guanethidine. The patients on methyldopa who complained of this effect had all voiced the same or more serious complaints when being treated with - the other two agents.

Side-effects were not recorded in 15 patients treated with methyldopa, compared with seven treated with guanoxan and seven with guanethidine. They were mainly the same patients, and in most cases the dose was low.

The red-cell, white-cell, and platelet counts, the haemoglobin value, and the serum alanine transaminase were determined in all the patients before the trial and at each change of drug. At no time did any patient present pathological values indicating bone-marrow or liver toxicity from the substances employed. Recently, cases of haemolytic anaemia were described in patients treated with methyldopa. A positive Coombs test was often seen, but though anaemia is a rare condition attention should be drawn to it in patients on long-term treatment with methyldopa. This complication was not encountered in the present trial.

\section{Discussion}

During the present study we have attached particular importance to a reduction in the recumbent blood pressure, and consequently the criteria for satisfactory control rest on this effect. It has therefore become difficult to compare our trial with several other studies, in which a reduction in the standing pressure is applied as a measure of the effect.

Oates et al. (1965) carried out a comparative study of guanethidine, methyldopa, and pargyline in 19 outpatients, who were given all three agents. This was not a blind trial. It was concluded that none of the substances had an absolute advantage over any of the others. However, methyldopa produced less postural hypotension, and in cases of identical blood pressure values in the standing position the recumbent blood pressure was reduced most markedly on methyldopa.

Johnston et al. (1966) compared 37 patients treated with methyldopa with 66 other patients who were on guanethidine. Some of the patients in each group received diuretics. "Good + fair" control was obtained in about $90 \%$ of both groups, but those on methyldopa had fewer and less-pronounced sideeffects. It was pointed out that the ability of the two substances to lower the recumbent blood pressure was identical.

It will be seen from our results that in a group of severe and moderate hypertensives receiving polythiazides the blood pressure in the lying position can be reduced satisfactorily and with mild or no side-effects in $85 \%$ of those on methyldopa, in $63 \%$ on guanoxan, and in $50 \%$ on guanethidine. If the group presenting the severe side-effects is included the percentages are 90,75 , and 63 respectively. Hence, methyldopa produced the most favourable results, and, as regards the sympatholytic agents, treatment with guanoxan is apparently more easily managed than treatment with guanethidine. The incidence of side-effects which prohibit an increase in dose is twice as high on guanethidine as on guanoxan.

In our opinion guanoclor should not be used in the treatment of hypertensives on an outpatient basis because of the frequent and severe side-effects.

Three patients could not be controlled satisfactorily on any of the drugs employed, not even if severe side-effects developed, but in all three cases the blood pressure could be reduced considerably by means of one or more of the drugs.
On the basis of the present trial we cannot assess the value of a combined treatment with the drugs concerned. Breckenridge and Dollery (1966) have shown that by combining methyldopa and a sympatholytic agent (bethanidine) favourable results can be obtained even in cases where methyldopa or bethanidine was without any greater effect or produced appreciable sideeffects when given alone.

The fact that tolerance may develop towards methyldopa and guanethidine during long-term treatment is not supported by our short-term trial. For this reason we cannot say anything about a possible tendency to development of tolerance towards guanoxan.

Montuschi and Lovel (1964) described the cases of two patients who developed signs of liver affection after treatment with guanoxan (and other agents). Peart and MacMahon (1964) carried out liver-function tests in their 69 patients and found no signs of any effect on this function. This applies also to the present trial. Cotton and Montuschi (1966) suggested that the drug might be hepatotoxic, and they announced further studies.

Although in our opinion there is not much basis for presuming that guanoxan has a hepatotoxic effect, this is presumably the reason why this drug has not yet been introduced into Denmark.

\section{Summary}

Forty patients with moderate and severe hypertension were treated with methyldopa, guanethidine, guanoxan, and guanoclor. The study was made on a double-blind basis.

Severe side-effects occurred after the administration of guanoclor, and consequently it had to be excluded from the trial.

The study seems to show that in cases where satisfactory response is not obtained by complete diuretic therapy methyldopa is the drug of choice to be added. In cases where methyldopa has no satisfactory effect a sympatholytic agent must be given. Our results indicate that guanoxan has an advantage over guanethidine in such treatment.

Pfizer Ltd. kindly supplied all the drugs used in the trial.

\section{REFERENCES}

Bayliss, R. I. S., and Harvey-Smith, E. A. (1962). Lancet, 1, 763. Breckenridge, A, and Dollery, C. T. (1966). Ibid., 1, 1074.

Brit. med. F., 1964a, 2, 37.

$1964 \mathrm{~b}, 2,238$.

Cass, R., Kuntzman, R., and Brodie, B. B. (1960). Proc. Soc. exp. Biol. (N.Y..), 103, 871.

Cotton, S. G., and Montuschi, E. (1966): Brit. med. F., 1, 51.

Daley, D., and Evans, B. (1962). Ibid., 2, 156.

Davey,

Davey, M. J., and Reinerth. D, and McMichael, J. (1960). Lancet, 1, 296.

Gillespie, L., Oates, J. A., Crout, J. R., and Sioerdsma, A. (1962). Circulation, 25, 281.

Johnson, P., Kitchin, A. H., Lowther, C. P., and Turner, R. W. D. (1966)." Brit. med. Ұ., 1, 133.

Lauwers, P., Verstraete, M., and Joossens, J. V. (1963). Ibid., 1, 295. Lawrie, T. D. V., Lorimer, A. R., McAlpine, S. G., and Reinert, H. (1964). Ibid., 1, 402.

Lowther, C. P., and Turner, R. W. D. (1963). Ibid., 2, 776.

Luke, R. A., and Kennedy, A. C. (1964). Ibid., 1, 27.

Luke, R. A., and Kennedy, A., and Plummer, A. J. (1959). Experientia (Basel), 15, 267.

Montuschi, E., and Lovel, T. W. I. (1964). Lancet, 2, 1339. Oates, J. A., Gillespie,

Science, 131, 189. Clark, M. A., Rousseau, P., and Lee, R. E. (1965). New Engl. भ. Med., 273, 729

Onesti, G. Brest, A. N., Novack, P., Kasparian, H., and Moyer, J. H. (1964). Amer. Heart \%., 67, 32

Page, I. H., and Dustan, H. P. (1959). F. Amer. med. Ass., 170, 1265

Peart, W. S., and MacMahon, M. T. (1964). Brit. med. Y., 1, 398.

Prescott, L. F., Buhs, R. P., Beattie, J. O., Speth, O. C., Trenner, N. R. ott, L. Bu, (1966). Circulation, 34, 308

and Lasagna, L.ilbo, H., and Bäcklund, H. (1961). Nord. Med., 66, 1112.

—_ Varnauskas, E., and Werkö, L. (1962). Acta med. scand., 171, 73. 